ISSN: 2528-9527

E-ISSN : 2528-9535

Yıl Year: 11

Cilt Volume: 17

Sayı Issue: 35

\title{
Swearer Zorbalık Ölçeğinin Türk Kültürüne Uyarlanması ve Geçerlilik, Güvenilirlik Analizi
}

DOI: 10.26466/opus.738264

\author{
* \\ Erkan Efilti *- Șerif Ayșe Özdemir** \\ * Doç Dr, Necmettin Erbakan Üniversitesi, Ahmet Keleşoğlu Eğitim Fakültesi, Konya/ Türkiye \\ E-Posta: efilti71@gmail.com \\ ORCID: $\underline{0000-0003-1158-5764}$ \\ **Y. L , Necmettin Erbakan Üni., Eğitim Bilimleri Ens., Meram/ Konya/ Türkiye \\ E-Posta: s.ozdemir.batur@gmail.com \\ ORCID: $\quad$ 0000-0002-9773-8479
}

\begin{abstract}
Öz
Bu çalışmada, Ortaokul öğrencileri Swear Zorbalık Ölçeğinin Türk kültürüne uyarlanması ve bu amaçla Swear Zorbalık ölçeğinin yapı geçerliğine ve güvenirliğine ilişkin kanıtlar saptanması amaçlanmıştır. Swear Zorbalık ölçeğin uyarlanmasında ilk aşama olarak Türkçeye çevirisi gerçekleştirilmiştir. Bu çeviriden sonra tekrar ölçeğgin kendi dili olan İngilizceye geri çevrilerek (Back-translation) uygulanmıştır. Geçerlilik çalışması sırasında uzmanlar tarafından çevirisi ve maddeleri incelenerek gerekli görülen düzenlemeler yapılmıştır. Pilot çalışmanın ardından ölçek Konya İl Milli Ĕ̆itim Müdürlüğ̈̈̈ne bağlı ortaokulların beşinci, altıncı, yedinci ve sekizinci sınıfların temsil eden 1048 öğrenciye uygulanmıştır. Açımlayıcı ve doğrulayıcı faktör analizi sonuçları Swear Zorbalık ölçeğin yapısal olarak tek boyuta ve yüksek bir geçerliğe sahip olduğunu göstermiştir. Swear Zorbalik ölçeğin tek boyutlu formunun Cronbach Alfa güvenirlik katsayısı ise 75'dir. Ayrıca ölçeğin madde-toplam korelasyonlar ve test tekrar test güvenirliği sonuçları sınanmış, bu kapsamda sonuçlar tartışılmıştır.
\end{abstract}

Anahtar Kelimeler: Akran zorbalı̆̆ı, ölçek, uyarlama, geçerlilik, güvenirlik, okul. 
ISSN: 2528-9527

E-ISSN : 2528-9535

Yıl Year: 11

Cilt Volume: 17

Sayı Issue: 35

Mart March 2021

Makalenin Geliș Tarihi Received Date. 16/05/2020

Makalenin Kabul Tarihi Accepted Date. 19/02/2021

\title{
Adaptation of the Swear Bullying Scale to Turkish Culture and Validity and Reliability Analysis
}

\begin{abstract}
In this study, it was aimed to adapt the Swear Bullying Scale to the Turkish culture, and to find evidence of the Swear Bullying scale's validity and reliability for this purpose. As a first step in the adaptation of the Swear Bullying scale, it was translated into Turkish and applied back to English, the language of the scale. During the validity study, the necessary translations were made by examining the translation and articles by the experts. After the pilot study, the scale was applied to 1048 students representing the fifth, sixth, seventh and eighth grades of secondary schools under the roof of Konya Provincial Directorate of National Education. Exploratory and confirmatory factor analysis results showed that the Swear Bullying scale has a structurally high dimension and a high validity. Cronbach Alpha reliability coefficient of the one-dimensional form of the Swear Bullying scale is .75. In addition, item-total correlations of the scale and test-retest reliability results were tested and results were discussed in this context.
\end{abstract}

Keywords: Peer bullying, scale, adaptation, validity, reliability, school. 


\section{Giriş}

Birey dünyaya gelmesi ile birlikte başka insanlarla etkileşime girme ihtiyacı duyar. İlk olarak aile bireyleri ile sonra da arkadaş ve çevresindeki kişiler ile sosyalleşme süreçleri başlamaktadır. Sosyalleşme süreci sağlıklı bir şekilde ilerlediğinde, bireyin duygusal, sosyal ve psikolojik olarak gelişimi olumlu yönde etkilenmektedir (Mooij, 2010; Hay, Payne, ve Chadwick, 2004). Sosyalleşme ortamlarından biri olan okul ve çevresi, öğrencilerin akran ilişkisi kurması için önemli mekânlardandır. Bu mekânlarda aynı yaşta ya da aynı gelişim düzeyinde olan kişiler arasında bir etkileşim oluşmaktadır (Rigby ve Johnson, 2005; Ogelman ve Erten, 2010; Van Doorn ve Verheij, 2010).

Akran ilişkilerinde, akranların birbirlerine sağladıkları destek ve güven özgüven ile sosyal becerileri artırmaktadır. Akranları tarafından benimsenen ve kabul gören çocukların okula olan uyumları ve kişisel gelişimleri başarılı bir şekilde sonuçlanmaktadır (Hay, Payne, ve Chadwick, 2004; Ladd, 2006).

Okulda yaşanan akran ilişkileri, deneyimleri her zaman olumlu şekilde sonuçlanmamaktadır. Olumsuz akran ilişkileri olan veya akranları ile ilişkisi olmayan öğrencilerin gelişimleri olumsuz olmaktadır. Bu durum okul öncesi dönemde başlayıp sonraki yılları da etkilemektedir. Öğrencilerin akranları tarafından reddedilmesi ve ya zorbalığa uğraması, ilerleyen yıllarda başarısızlığa, okulu terk etmeye, suçlara karışma hatta intihara kadar çeşitli olumsuz etkilerde bulunmaktadır. (Walker, 2004; Hay, Payne, ve Chadwick, 2004; Pellegrini ve Long, , 2002; Kapç1, 2004; Olweus D. , 2005; Gini e Pozzoli, 2013).

Geçmiş tarihte akran zorbalığı çocuk gelişiminde normal bir dönem olarak görülmüştür. Zamanla akran zorbalığının artması ve çocuklar üzerinde olumsuz etkiler bıraktığının anlaşılmasından sonra bu konu hakkında araştırmalar artmıştır. Akran zorbalığının birey üzerinde bıraktığı etkilerin görülmesi ile çocukluk döneminde gelişimin bir parçası olmadığ 1 kabul edilmiştir. (Berger, 2007; Ladd, 2006; Vermande, Meulenr, Aleva, Olthof, ve Goossens, 2011).

Zorbalık hakkında ilk tanımlama Dan Olweus (1993) tarafından yapılmıştır. Olweus'e göre zorbalık; "bir kişi ya da bir grup tarafından kendisinden daha az güçlü olan kişiye yönelik fiziksel ve psikolojik olarak kasıtlı ve tekrarlayıcı biçimde baskı uygulanması" olarak tanımlanmıştır (Olweus D. , 1993). 
Tüm dünyada bir mesele haline gelen akran zorbalığı, Türkiye'de de çok kapsamlı ve küçümsenmeyecek bir problem halini almıştır. (Olweus ve Limber, 2010; Deveci , Açık, ve Ayar, 2008). Hemen hemen okulların hepsinde meydana gelen akran zorbalığında o ortamda bulunan her kişi bu eylemde bir rol almaktadır. Genellikle okulda akranlarından fiziksel (arkadaşlarından uzun, kısa, şişman, zayıf, fiziksel engeli olan veya özel gereksinimli) ve ya duygusal (içedönük, sessiz, pısırık, korkak, fazla arkadaşı veya statüsü olmayan) olarak farklılık gösteren öğrenciler zorbalar tarafından kurban olarak seçilmektedir. (Huitsing, van der Meulen -van Dijk, ve Veenstra, 2012; Vermande, Meulenr, Aleva, Olthof, ve Goossens, 2011; Pişkin, Okul zorbalı̆̆ı: Tanımı, türleri, ilişkili olduğu faktörler ve alınabilecek önlemler, 2002; Rigby ve Johnson, 2005). Akran zorbalığını uygulayanlar ise kurbanlarından daha güçlü ve saldırgan davranışa sahip elebaşı rolü alan kişilerdir. Zorbalar kurbanları ile empati kuramamakta ve orantısız bir şekilde güç uygulamaktadırlar (Vermande, Meulenr, Aleva, Olthof, e Goossens, 2011; Mooij, 2010; Gini ve Pozzoli, 2013). Akran zorbalığında rol alan diğer kişi ise seyirci veya şahit olarak adlandırılan kişidir. Seyirci veya şahit olan kişi akran zorbalığın sırasında sessiz kalan, kurbana destek çıkan veya zorbaya yardımcı olan kişi olarak tanımlanmaktadır. (Huitsing, van der Meulen -van Dijk, ve Veenstra, 2012).

Akran zorbalığı ile hayatın her alanında karşılaşmak mümkündür. (Aquino ve Bradfield, 2000; Pellegrini ve Long, , 2002; Smith ve Ananiadou, 2003). Araştırmalara göre zorbalığın üçte ikisi okullarda meydana gelmektedir (Van Doorn \& Verheij, 2010). Okulun her tarafında akran zorbalığı uygulanmaktadır. Zorbalar genellikle kimsenin müdahale edemeyeceği yerler olarak okul bahçesi, koridor ve kantini tercih etmektedirler. Bundan dolayı zorbalığa uğrayan öğrenciler o ortamlardan uzak durmaktadırlar. (Huitsing, van der Meulen -van Dijk, \& Veenstra, 2012; Whitted \& Dupper, 2005). Akran zorbalığ1 yoğun olarak ilkokulda görülmekte lise yıllarında azalma göstermektedir (Mooij, 2010; Fekkes, Pijpers , ve Verloove-Vanhorick , 2005; Smith, Madsen , ve Moody, 1999).

Akran zorbalığında zorbalar, seçtikleri kurbana kasıtlı ve tekrarlayıcı şekilde baskı uygulamaktadırlar. Araştırmacılar tarafından elde edilen verilere göre zorbaların farklı yöntemler uyguladıkları tespit edilmiştir (Baar, 2012; Li, 2007; Glover, Gough, Johnson, ve Cartwright, 2010; Card, Stucky, 
Sawalani, ve Little, 2008; Besag, 1995; Pekel-Uludağlı ve Uçanok , 2005). Verilerin toplamında beş tür zorbalık eylemi öne çıkmaktadır. Bunlar; Fiziksel zorbalık, kurbana fiziksel güç uygulanma (vurma, itme, tükürme), Sözel zorbalık olarak sözlü güç uygulama (lakap takma, alay etme, küfretme), İlişkisel zorbalık olarak duygusal güç uygulama (gruptan dışlamak, arkasından konuşmak, sosyal statüsünü zedeleme) Cinsel zorbalık olarak cinsel güç uygulama (sözlü veya fiziksel taciz etme) ve son yıllarda teknolojinin gelişmesi ile siber zorbalık olarak online güç uygulamadır (sosyal medya üzerinden kurban hakkında resim, video, dedikodu veya yalan haber yayma). (Pişkin, 2002; Olweus D., 2005; Vandevelde ve De Groef, 2015; Fekkes, Pijpers , ve Verloove-Vanhorick , 2005; Baar, 2012; Tokunaga, 2010; Pergolizzi, ve diğerleri, 2011; Rivers ve Smith, 1994; Yang ve Salmivalli, 2013; Van der Wal , De Wit, ve Hirasing, 2003).

Ülkemizde Akran zorbalığının artması ile okullarda zorbalığın yaygınlığı ve sıklığı hakkında araştırmalar yoğunlaşmıştır. (Bayraktar, 2009; Gültekin, 2003; Cağrı, 2010; Deveci , Açık, ve Ayar, 2008; Doğan-Ateş ve Yağmurlu, 2010; Kapçı, 2004; Koç Z. , 2006; Ogelman ve Erten, 2010; Pekel-Uludağlı \& Uçanok , 2005; Pişkin, 2002). Bu konu hakkında yapılan araştırmalarda farklı ölçüm araçları kullanılmaktadır. Bunlar; akran bildirimi (peer nomination), öğretmen değerlendirmesi (teacher ratings/nomination) ve kendini bildirim (self-report) ölçekleri olarak sıralanmaktadır. Akran zorbalığı hakkında veri toplamı yöntemi olarak bu ölçekler tek başına ya da birlikte kullanılmaktadır.

Alanda yapılan araştırmalarda çoğunlukla veri toplama aracı olarak akran bildirimi ile kendi bildirim türü ölçeklerinin kullanıldığı tespit edilmiştir (Boulton ve Peter , 1994; Dölek, 2002; Gültekin, 2003; O'Moore \& Hillery, 1989; Pekel-Uludağlı ve Uçanok , 2005; Pellegrini, Bartini, ve Brooks, 1999). Akran bildirimi (Pellegrini ve Bartini, 2000; Schwartz, 2000; Perry, Kusel, ve Perry, 1988).

Akran zorbalığı hakkında ilk ölçek Dan Olweus tarafından 1993 yılında geliştirilmiştir. (Olweus, 1993). Geliştirilen ölçek kendini bildirim türünden olup Olweus Zorba/ Kurban Anketi (Olweus Bully/Victim Questionnaire)" olarak adlandırılarak uluslararası çalışmalarda kullanılmıştır. Dölek (2002) tarafından uyarlanarak ülkemizde araştırmacıların hizmetine sunuluştur. Olweus tarafından hazırlanan ölçek 40 maddeden oluşmaktadır ve uygulanan zorbalık çeşitleri hakkında birçok bilgi vermektedir. 
Diğer bir akran zorbalığı ölçeği Rigby ve Slee (1993) tarafindan geliştirilmiştir. Ölçek "Akran İlişkileri Ölçeği” (Peer Relations Questionnaire-PRQ) olarak adlandırılmışır ve birçok araştırmalarda zorbalığın diğer faktörlerle ilişkilerini belirlemek amacıyla uluslararası çalışmalarda veri toplama yöntemi olarak kullanılmıştır (Pellegrini ve Long, , 2002; Peterson ve Rigby, 1999; Salmivalli ve Nieminen, 2002). Ölçek toplamda 20 maddeden oluşarak zorbalık yapma, kurban olma, yandaş olma ve olumlu sosyal davranışlar hakkında veri vermektedir.

Akran zorbalığı çok kapsamlı durum olduğundan dolayı zorbalığın çeşitli boyutlarını incelemek için Mynard ve Joseph (2000) tarafından (Çok Boyutlu Kurban Ölçeği - Multidimensional Victimization Scale) hazırlanmıştır. Ölçekte akran zorbalığına maruz kalma düzeylerini belirlemek amacıyla 16 soru bulunmaktadır. Mynard ve Joseph hazırlamış oldukları ölçek ülkemize Gültekin ve Sayıl (2005) tarafından uyarlanarak “Akran Zorbalığı Kurbanlarını Belirleme Ölçeği" olarak adlandıralar alana katkı sağlamaktadır (Akgün, 2005; Pekel, 2004; Şirvanl1-Özen, 2006)

Dünyadaki diğer ülkelerde olduğu gibi ülkemizde de akran zorbalığında artış görülmektedir. Bu artışın yaygınlığını ve sıklığını belirlemek amacıyla birçok çalışma yapılmıştır. Ülkemizde yapılan çalışmalarda akran zorbalığının yaygınlığı, yaş, cinsiyet gibi değişkenlerle ilişkisi sorgulanmıştır. (Dölek, 2002; Kapçı, 2004; Alikaşifoğlu, ve diğerleri, 2004; Gültekin ve Sayıl, 2005; Alikaşifoğlu, Erginöz, Ercan, Uysal, ve Albayrak -Kaymak, 2007; Yildirim, 2001; Şirvanlı-Özen, 2006). Yapılan çalışmalarda kullanılan ölçekler uluslararası ölçekler olup ülkemize uyarlanması yapılan akran bildirimi ve ya kendini bildirim ölçeklerinden oluşmaktadır (Dölek, 2002; Gültekin Z. , 2003; Kartal, 2008). Kullanılan ölçeklerde akran zorbalığ hakkında yeterli bilgiye ulaşılmamaktadır. Swearer akran zorbalığı ölçeği hem bir akran bildirimi hem de kendini bildirim ölçeği olup akran zorbalığını 4 boyuttan: zorba, kurban, şahit ve özellikle zorbalık hakkındaki tutumu ele alarak bu alanda bir gereksinimi karşılayacağ 1 düşünülmektedir.

Akran zorbalığı hakkında daha kapsamlı veri toplamak amaçlı Swearer akran zorbalığı ölçeğinin Türkçeye ve Türkiye'ye uyarlanarak, geçerlilik, güvenirlik çalışması yapılması amaçlanmıştır. 


\section{Yöntem}

\section{Çalışma Grubu}

Araştırma ölçeği 2019- 2020 eğitim öğretim yılında Konya İl Milli Eğitim Müdürlüğü izni ile Milli Eğitim Müdürlüğü'ne bağlı ortaokulların besinci, altıncı, yedinci ve sekizinci sınıflarını temsil eden 1048 öğrenciye uygulanmıştır. Araştırmaya dâhil edilen ortaokul öğrencilerinin \%45,4'ü $(\mathrm{n}=476) \mathrm{kız}$ ve $\% 54,6$ 's1 (n=572) erkektir. Öğrencilerin \%24,1'i ( $n=253)$ beş, \%26,7'sinin $(\mathrm{n}=280)$ alt, $\% 33,5^{\prime}$ inin $(\mathrm{n}=351)$ yedi ve \%15,6'sinın ise ( $\left.\mathrm{n}=164\right)$ sekizinci sinıfta öğrenim görmektedir. Araştırmaya dâhil edilen öğrencilerin \%47,6's1 (n=499) bir zorbalığa uğradığını ve \%52,4'ü $(n=549)$ ise herhangi bir zorbalığa uğramadığını ifade etmiştir.

\section{Veri Toplama Araci}

Swearer Zorbalı̆̆a Yönelik Tutum Ölçeği: Araştırma kapsamında, Swearer Zorbalığa Yönelik Tutum Ölçeği (The Bully Attitudinal Scale) Türkçeye uyarlanarak kullanılmıştır. Uyarlanan ölçek, Swearer ve arkadaşları (2008) tarafından geliştirilmiştir. Ölçme aracı tek faktörlü bir yapıya sahiptir ve 14 maddeden oluşmaktadır. Katılımclardan ölçekte yer alan her bir maddenin kendileri için ne kadar doğru olduğunu belirtmeleri istenmektedir. Ölçek maddeleri 1 (tamamen yanlış) ile 5 (tamamen doğru) arasındaki değerler ile derecelendirilmektedir. Ölçek puanı hesaplanırken tüm maddelere verilen cevapların ortalaması alınmaktadır. Ölçekten alınan yüksek puanlar zorbalığa yönelik olumsuz tutumların daha fazla olduğunu işaret etmektedir. Düşük puanlar ise daha fazla sosyal tutum ve davranışların varlığına işaret etmektedir. Swearer ve arkadaşları, ölçek için hesapladıkları alfa iç tutarlılık katsayısını 0,71 olarak raporlanmıştır.

Ölçme Aracının Türkçeye Çeviri Süreci: Ölçme aracının Türkçeye uyarlanmasına karar verildikten sonra, sorumlu yazar (Dr. Swearer) ile iletişime geçilmiş ve ölçeğin uyarlanabilmesi için izin alınmıştır. Çeviri sürecinde çevirigeri çeviri yöntemi temel alınmıştır. Birinci adımda, ölçme aracının İngilizce formu, özel eğitim ve psikolojik danışma ve rehberlik alanında uzman olan ve iyi düzeyde İngilizce bilen iki akademisyen tarafından Türkçeye çevrilmiştir. Bu aşamadan sonra iki uzmanın çevirileri incelenerek ölçme aracının 
Türkçe taslak formu elde edilmiştir. Sonraki aşamada ise ölçme aracının Türkçe taslak formu, özel eğitim ve psikolojik danışma ve rehberlik alanında uzman olan ve iyi düzeyde İngilizce bilen farklı iki akademisyen tarafından İngilizceye çevrilmiştir. Son aşamada ise ölçme aracının özgün formu ile Türkçe taslak formdan elde edilen İngilizce form, İngilizce okutmanı olan iki uzman tarafından karşılaştırılarak incelenmiştir. Uzmanlar, Türkçe taslak formdan elde edilen İngilizce formun özgün formla aynı görüşleri yansıttığını belirtmiştir.

Türkçe form, kültürel bağlam, dilbilim, araştırma yöntembilim ve ölçme değerlendirme ölçütleri açısından da incelenmiştir. Bunun için alan uzmanlarının görüşlerine başvurulmuştur. Uzman görüşleri temel alınarak ölçek maddelerinde bazı revizyonlar gerçekleştirilmiştir. Bu aşamadan sonra ölçeğin Türkçe taslak formunun nihai haline ulaşılmıştır. Geçerlilik ve güvenirlik çalışmaları gerçekleştirilmeden önce Türkçe form otuz öğrenciye uygulanarak ölçek maddeleri ile ilgili görüşleri alınmıştır. Öğrenciler ölçme aracında yer alan maddelerin açık ve net bir şekilde yazıldığını, anlaşılmayan bir noktanın bulunmadığını ifade etmiştir.

\section{Bulgular}

\section{Geçerlilik Ve Güvenirlik Çalışması Sonuçlan}

Swearer Zorbalığa Yönelik Tutum Ölçeğinin geçerliği açımlayıcı (AFA) ve doğrulayıcı (DFA) faktör analizi ile incelenmiştir. Ölçeğin güvenirliği ise Cronbach Alfa iç tutarlılık katsayısı hesaplanarak belirlenmiştir. AFA analizi için 490 öğrenciye ulaşılmış ve bu öğrencilerin verileri kullanılarak analiz gerçekleştirilmiştir. DFA için ise 558 öğrenciye ulaşılmış ve bu öğrencilerin verileri kullanılarak ölçme aracının tek faktörlü yapısı test edilmiştir. Ölçme aracı için hesaplanan Alfa katsayısı ise 1048 öğrencinin verisi kullanılarak hesaplanmıştır.

\section{Açımlayıcı Faktör Analizi Sonuçlan}

Açımlayıcı faktör analizi öncesi karşılanması gereken bazı varsayımlar kontrol edilmiştir. Bu doğrultuda, ilk olarak örneklem sayısının faktör analizi için yeterli olup olmadığı araştırılmıştır. KMO katsayısı hesaplanarak örneklem sayısının yeterliliği hakkında bilgi edinilebilmektedir. KMO'dan elde edilen veriler 1'e yaklaştıkça mükemmel, 0.50'nin altında ise kabul edilemez olduğu 
söylenebilir (Tavşancıl, 2005) Bu araştırmada KMO katsayısı 0,70 olarak bulunmuş ve örneklem sayısının yeterli olduğu gözlenmiştir. Bir sonraki adımda, Bartlett küresellik testi katsayısı hesaplanmış ve elde edilen katsayının anlamlı olduğu gözlenmiştir ( $\chi 2=1151,89 ; \mathrm{Sd}=36 ; \mathrm{p}<0,001)$. Elde edilen sonuçlar, verilerin faktör analizine uygun olduğunu göstermiştir (Çokluk, Şekercioğlu, \& Büyüköztürk, 2012).

Temel bileşenler analiz yöntemi uygulanarak faktör analizi gerçekleştirilmiştir. Ölçme aracının orijinal formu tek faktörlü olduğundan ölçek maddeleri tek faktöre zorlanarak analize dâhil edilmiştir. Faktör analizinde, faktör yükü kesim noktası 0,32 olarak belirlenmiştir. 0.32 ve daha yüksek faktör yüküne sahip maddeler varyansa önemli ölçüde bir katkı sunmaktadır (Tabachnick \& Fidell, 2007). Faktör analizi sonucunda, kesim noktasının altında faktör yüküne sahip 5 madde ( $\mathrm{m} 1$, m3, m5, m6 ve m11) tespit edilmiştir. Bu maddeler tek tek çıkarılarak faktör analizi yenilenmiştir. Faktör analizi sonucunda ölçme aracında 9 maddenin kaldığı gözlenmiştir. Swearer Zorbalığa Yönelik Tutum Ölçeğinde bulunan maddelerin faktör yükleri ve açıklanan varyans yüzdesi Tablo 1'de gösterilmiştir.

Tablo 1. Swearer Zorbahı̆a Yönelik Tutum Ölçeğinin Faktör Yapısı

\begin{tabular}{|c|c|c|c|c|c|}
\hline \multirow[b]{2}{*}{ Faktör } & \multirow[b]{2}{*}{ Madde No } & \multirow{2}{*}{$\begin{array}{l}\text { Madde } \\
\text { Toplam } \\
\text { Korelasyonu }\end{array}$} & \multirow{2}{*}{$\begin{array}{l}\text { Madde Ortak } \\
\text { Varyansı }\end{array}$} & \multirow{2}{*}{$\frac{\text { Faktör }}{\text { Yükü }}$} & \multirow{2}{*}{$\begin{array}{l}\text { Açıklanan } \\
\text { Varyans (\%) }\end{array}$} \\
\hline & & & & & \\
\hline \multirow{9}{*}{$\begin{array}{l}\text { Swearer Zorbalığa Yönelik Tutum } \\
\text { (Öz-değer=3,16) }\end{array}$} & $\mathrm{m} 10$ & 0,64 & 0,68 & 0,82 & \multirow{9}{*}{35,15} \\
\hline & $\mathrm{m} 12$ & 0,60 & 0,56 & 0,75 & \\
\hline & $\mathrm{m} 7$ & 0,55 & 0,54 & 0,73 & \\
\hline & $\mathrm{m} 8$ & 0,41 & 0,34 & 0,58 & \\
\hline & $\mathrm{m} 2$ & 0,38 & 0,26 & 0,51 & \\
\hline & $\mathrm{m} 4$ & 0,38 & 0,26 & 0,51 & \\
\hline & $\mathrm{m} 13$ & 0,34 & 0,21 & 0,46 & \\
\hline & $\mathrm{m} 14$ & 0,30 & 0,16 & 0,40 & \\
\hline & $\mathrm{m} 9$ & 0,32 & 0,16 & 0,40 & \\
\hline
\end{tabular}

AFA sonucunda, ölçekte bulunan maddelerin faktör yüklerinin 0,40 ile 0,82 arasında değiştiği gözlenmiştir. Tek faktörlü yapının öz değeri 3,16 olarak hesaplanmıştır. Tek faktörlü ölçek toplam varyansın \%35,15'ini açıklamıştır. Tek faktörlü ölçeklerde açıklanan varyansın \%30 ve daha fazla olması yeterli görülmektedir (Büyüköztürk, 2006). 


\section{Doğrulayıcı Faktör Analizi Sonuçlar}

Swearer Zorbalığa Yönelik Tutum ölçeğinin AFA ile keşfedilen tek faktörlü yapısı DFA uygulanarak test edilmiştir. DFA ile önceden belirlenmiş bir yapının toplanan veriler ile ne derece uyumlu olduğu belirlenmektedir (Çokluk, Şekercioğlu, \& Büyüköztürk, 2012). DFA sonucunda, uyum değerleri hesaplanarak model veri uyumu değerlendirilmektedir. Swearer Zorbalığa Yönelik Tutum ölçeğinin tek faktörlü yapısına ait uyum değerleri Tablo 2' de yer almaktadır.

Tablo 2. Swearer Zorbalı̆̆a Yönelik Tutum Ölçeğinin Tek Faktörlü Yapısına Ait Uyum Değerleri

\begin{tabular}{lllll}
\hline Ölçüt & İyi Uyum & $\begin{array}{l}\text { Kabul } \\
\text { Edilebilir Uyum }\end{array}$ & $\begin{array}{l}\text { Elde Edilen } \\
\text { Değerler }\end{array}$ & Kaynak \\
\hline$\left(\chi^{2} /\right.$ sd) & $\leq 3$ & $\leq 4-5$ & 3,37 & (Byrne, 1989) \\
\hline RMSEA & $\leq 0,05$ & $0,06-0,08$ & 0,07 & (Browne ve Cudeck, 1993) \\
\hline SRMR & $\leq 0,05$ & $0,06-0,08$ & 0,04 & (McDonald ve Marsh, 1990) \\
\hline CFI & $\geq 0,95$ & $0,90-0,94$ & 0,98 & (Tanaka ve Huba, 1985; Jöreskog \\
\hline PCLOSE & $>0,01$ & $>0,05$ & 0,09 & ve Sörbom, 1993) \\
\hline GFI & $\geq 0,90$ & $0,89-0,85$ & 0,98 &
\end{tabular}

Tablo 2 incelendiğinde, Swearer Zorbalığa Yönelik Tutum ölçeğinin tek faktörlü modeli ile eldeki verilerin genel olarak iyi düzeyde uyum gösterdiği anlaşılmaktadır. Bu sonuca göre, ölçme aracının tek faktörlü yapısı doğrulanmiştır. DFA sonucunda ölçekte bulunan maddelerin faktör yüklerinin 0,38 ile 0,71 arasında değiştiği gözlenmiştir. Test edilen tek faktörlü model Şekil 1'de gösterilmiştir. Modele yer alan yol katsayılarının her biri istatistiksel olarak anlamlıdır $(\mathrm{p}<0,001)$. 


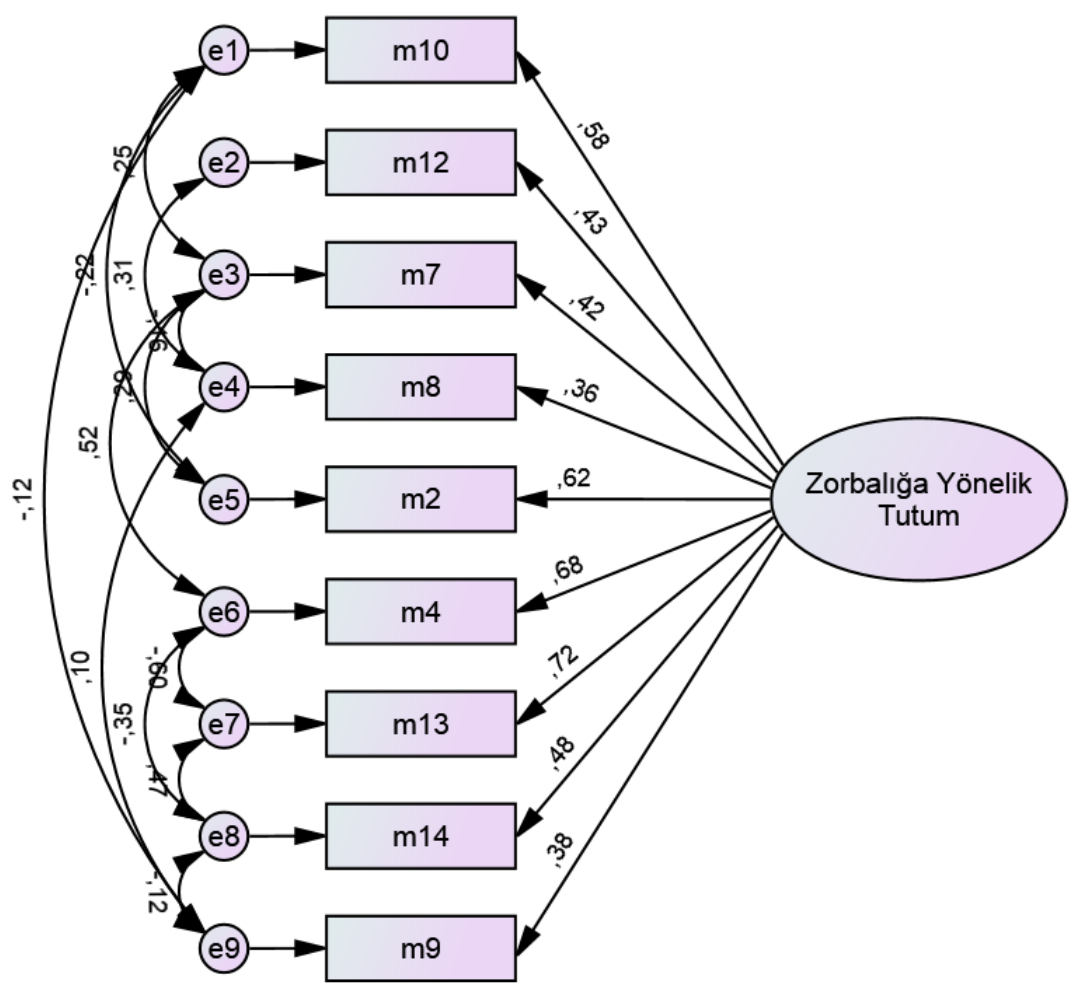

Şekil 1. Swearer Zorbahı̆a Yönelik Tutum Ölçeğine Ait Tek Faktörlü Modelin DFA Sonuçlar, $\chi 2=50,49 ; s d=15 ; p<0,001$

\section{Güvenirlik Analizi Sonuçlarn}

Swearer Zorbalığa Yönelik Tutum ölçeğinin güvenirliğini belirlemek için Cronbach alfa iç tutarlılık katsayısı hesaplanmıştır. Bu katsayısının 0,70-0,80 arasında değerler alması iç tutarlılı̆̆ bağlı güvenirliğin yeterli düzeyde olduğunu işaret etmektedir (Özdamar, 2004). Ölçek için hesaplanan alfa katsayısı 0,74'tür (Tablo3). Bu katsayısı, ölçeğinin iç tutarlılığa bağlı güvenirliğinin yeterli düzeyde bulunduğunu göstermiştir.

Tablo 3. Swearer Zorbalı̆̆a Yönelik Tutum Ölçeğine Ait Alfa Katsayısı

\begin{tabular}{lll}
\hline Ölçek & Madde sayısı & Cronbach Alfa \\
\hline Zorbalı̆ga Yönelik Tutum & 9 & 0,74 \\
\hline
\end{tabular}




\section{Test Tekrar Test Güvenirliği Sonuçlarn}

Swearer Zorbalığa Yönelik Tutum Ölçeğinin zaman içinde tutarlı ölçümler yapıp yapmadığını belirlemek için test tekrar test yöntemi temel alınarak korelasyon katsayısı hesaplanmıştır. Bu doğrultuda, ölçme aracı bir hafta arayla araştırmaya dâhil edilen öğrenciler arasından seçilen 50 öğrenciye iki defa uygulanmıştır. İki uygulama arasındaki ilişkiyi incelemek için Pearson korelasyon katsayısı hesaplanmışır (Tablo 4).

Tablo 4. Test Tekrar Test Güvenirliğine İlişkin Betimsel Bilgiler ve Pearson Korelasyon Korelasyon Katsayıları

\begin{tabular}{llcclll}
\hline Ölçek & Uygulama & $\mathbf{N}$ & $\overline{\boldsymbol{X}}$ & Ss & $\mathbf{R}$ \\
\hline \multirow{2}{*}{1} & İlk uygulama & 50 & 1,69 & 0,51 & \multirow{2}{*}{$0,84^{* *}$} \\
\cline { 2 - 6 } & Son uygulama & 50 & 1,68 & 0,50 & \\
\hline
\end{tabular}

$" p<0,01$

Tablo incelendiğinde, ilk uygulama ve son uygulamada elde edilen toplam puan ortalamalarınin sirasiyla $1,69(S s=0,51)$ ve $1,68(S s=0,50)$ olarak hesaplanmıştır. Bir haftalık zaman farkına rağmen iki uygulama sonucunda elde edilen puan ortalamalarının birbirine oldukça yakın olduğu gözlenmiştir. İki uygulama sonucunda elde edilen puan ortalamaları arasında yüksek düzeyde pozitif yönlü ve anlamlı bir ilişki bulunmuştur $(\mathrm{r}=0,84 ; \mathrm{p}<0,01)$. Elde edilen bu sonuç, ölçeğin kararlı bir yapısının olduğunu işaret etmiştir.

\section{Ayırt Edici Geçerlik Analizi Sonuçları}

Araştırmada, ölçme aracının zorbalığa yönelik tutumları yüksek ve düşük olan öğrencileri ayırt etmede ne derecede başarılı olduğunu incelemek için üst \%27 ile alt \%27 grupların her maddeden aldığı puan ortalamaları karş1laştırılmıştır. Grupların puan ortalamalarını karşılaştırmak için bağımsız örneklem $\mathrm{t}$ testi uygulanmıştır. Elde edilen sonuçlar Tablo 5'te gösterilmiştir. 
Tablo 5. Swearer Swearer Zorbalı̆̆a Yönelik Tutum Ölçeği Maddelerinin Madde Toplam Korelasyon Değerleri ve Ayırt Edicilik Düzeyleri

\begin{tabular}{llll}
\hline Ölçek & Maddeler & $\begin{array}{l}\text { Madde toplam } \\
\text { korelasyonu }\end{array}$ & $\begin{array}{l}\mathrm{T} \\
\text { (Üst \%27- alt \%27) }\end{array}$ \\
\hline & $\mathrm{m} 2$ & 0,54 & $-17,56^{* *}$ \\
& $\mathrm{~m} 4$ & 0,52 & $-12,21^{* *}$ \\
Zorbalığa Yönelik Tutum & $\mathrm{m} 7$ & 0,48 & $-10,54^{* *}$ \\
& $\mathrm{~m} 8$ & 0,33 & $-10,99^{* *}$ \\
& $\mathrm{~m} 9$ & 0,33 & $-22,37^{* *}$ \\
& $\mathrm{~m} 10$ & 0,48 & $-8,44^{* *}$ \\
& $\mathrm{~m} 12$ & 0,42 & $-7,95^{* *}$ \\
& $\mathrm{~m} 13$ & 0,60 & $-18,76^{* *}$ \\
& $\mathrm{~m} 14$ & 0,38 & $-12,89^{* *}$ \\
\hline
\end{tabular}

${ }^{* *} \mathrm{p}<0,01$

Tablo 5 incelendiğinde, ölçek maddelerinin madde toplam korelasyon değerlerinin 0,33 ile 0,60 arasında değişen değerler aldığı anlaşılmaktadır. $\mathrm{Bu}$ değerler ölçek maddelerinin bulundukları faktörler ile orta düzeyde ilişkili olduğunu, ölçeğin iç tutarlılığının yeterli bulunduğunu göstermektedir. Ayrıca, ölçek maddelerinin her birinin zorbalığa yönelik tutumları yüksek ve düşük olan bireyleri ayırt etmede başarılı olduğu gözlenmiştir. Üst grupta yer alan bireylerin her maddeden almış oldukları puanların ortalaması, alt grupta yer alan bireylerinkinde göre anlamlı olarak daha yüksektir.

\section{Sonuç}

Geçerlilik ve güvenirlik analizi sonucunda, Swearer Swearer Zorbalığa Yönelik Tutum Ölçeğinin 9 maddeden oluştuğu ve tek faktörlü bir yapıya sahip olduğu gözlenmiştir. Tek faktörlü ölçek toplam varyansın önemli bir oranını açıklamıştır. Doğrulayıcı faktör analizi sonucunda, ölçme aracının tek faktörlü yapısı doğrulanmıştır. Hesaplanan alfa katsayısı ölçeğin iç tutarlılı̆̆ının yeterli düzeyde olduğunu göstermiştir. Test tekrar test güvenirlik analizi sonuçları ölçeğin kararlı bir yapısının olduğunu işaret etmiştir. Ayırt edici geçerlik sonuçlarına göre ise ölçek maddelerinin her birinin zorbalığa yönelik tutumları yüksek ve düşük olan öğrencileri ayırt etmede başarılı olduğunu göstermiştir.

Bu nedenle ortaokul düzeyinde zorbalık konusunda, ölçek geliştirme sürecine dayalı olarak geçerli, güvenilir ve uygulaması kolay bir ölçme ölçeğin geliştirilmesi sağlanmış ve tüm bu süreç açık bir şekilde tanımlanmıştır. Uzman görüşleri ve literatür taramasına dayalı olarak içerik ve uyarlama geçer- 
liliği sağlanan ölçeğin, doğrulayıcı ve açımlayıcı faktör analizleri ile tek boyutlu ve yüksek bir yapı geçerliliğine sahip olduğu kanıtlanmıştır. Devellis'e (2003) göre ölçek uyarlaması gerçekleştirilirken yapı ve içerik geçerliliğinin hem istatistiksel hem de mantıksal açıdan test edilmesi önem arz etmektedir (DeVellis, 2003). İstatistiksel boyutta açımlayıcı ve doğrulayıcı faktör analizleri, ortaya çıkan boyutların varyans düzeyleri ve faktör yüklerinin belirli kriterleri taşıması gerekir. Mantıksal açıdan ise çeviri, tersine çeviri, kapsamlı bir literatür taraması ve uzman görüşlerinin alınması ölçek geliştirme sürecinin önemli unsurlarıdır. Tüm bu yönleriyle ‘Swear Zorbalık Ölçeğinin' Türk Kültürüne uyarlanması sürecinde yapı ve içerik geçerliğini yüksek tutmak için istatistiksel ve mantıksal işlemlerin birçoğu gerçekleştirilmiştir. Bu süreçte ölçeğin geçerliğine ilişkin ortaya çkan değerler kabul edilebilir ölçütlerin oldukça üzerinde çıkmıştır.

Bu ölçek geliştirme çalışmasının diğer önemli bir boyutu ise 'Swear Zorbalık Ölçeğinin' güvenirliliğine ilişkin bulgulardır. Rackwitz'e (2000) göre Likert tipinde ya da eşit aralıklı ölçek formlarında çok sayıda güvenirlilik yöntemi kullanılmasına rağmen en etkililerinden birisi Cronbach Alfa tekniğidir (Rackwitz, 2000). Bu kapsamda ortaokul örnekleminde Swear Zorbalık Ölçeğinin Cronbach Alfa güvenirlik katsayısı hesaplanmış ve .75 olarak bulunmuştur. Barabady ve Kumar'a (2008) göre yeni geliştirilen bir ölçeğin güvenirlik katsayısı 0,70'in üzerinde olması gerekir (Barabady \& Kumar, 2008). Bu yönüyle Swear Zorbalık Ölçeği için hesaplanan Cronbach Alfa katsayısı, ölçeğin yüksek bir iç tutarlılığa ve güvenirliğe sahip olduğunu göstermektedir. Sonuç olarak 'Swear Zorbalık Ölçeği' Türkiye koşullarında ortaokul öğrencilerinin öz değerlendirmelerine dayalı olarak ortaya konan içeriğiyle kültürel bağlamda geliştirilmiş, güvenirlilik ve yapı geçerliği test edilmiş bir ölçektir. Bu ölçeğin Türkiye'de farklı okullarda uygulanmasıyla, öğrenciler açısından zorbalık davranışının ne düzeyde bir etki ortaya çıkardığı saptanabilecek ve bu doğrultuda okullarda rehberlik ve öğretim faaliyetlerine ilişkin sağlıklı stratejiler geliştirilmesine bilimsel temelde veri sağlayacaktır. Ayrıca geliştirilen ölçek, ortaokulda öğrenim gören öğrencilere yöneliktir. Gelecekte zorbal1k konusundaki araştırma ve ölçek geliştirme çalışmalarının ilkokul ve lise dönemlerdeki öğrencilere odaklanması bu konudaki önemli boşluğu dolduracaktır. Geliştirilen ölçeğin farklı okul kademeleri ve eğitim kurumlarında öğrenim gören öğrenci grupları üzerinde test edilmesi ve gelecekte ölçeğin norm çalışmalarının yapılması önerilir. 


\title{
EXTENDED ABSTRACT
}

\section{Adaptation of the Swear Bullying Scale to Turkish Culture and Validity and Reliability Analysis}

\author{
Erkan Efilti - Şerif Ayşe Özdemir \\ Necmettin Erbakan University
}

Students being rejected or bullied by their peers have various negative effects, from failure to school dropout, involvement in crimes and even suicide in the following years. (Walker, 2004; Hay, Payne, and Chadwick, 2004; Pellegrini and Long, 2002; Kapç1, 2004; Olweus D., 2005; Gini e Pozzoli, 2013). With the increase in peer bullying in our country, researches has more focused on prevalence and frequency of bullying in schools. (Bayraktar, 2009; Gültekin, 2003; Cağrı, 2010; Deveci, Açık, and Ayar, 2008; Doğan-Ateş and Yağmurlu, 2010; Kapçı, 2004; Koç Z., 2006; Ogelman and Erten, 2010; Pekel-Uludağlı and Uçanok, 2005; Pişkin, 2002). Different methods/tools are used in studies on this subject. These are; It is listed as peer nomination, teacher ratings / nomination and self-report scales. These scales are used alone or together as a data collection method on peer bullying.

According to conduct field research, it has been determined that peer reporting and self-report type scales are mostly used as a data collection tool (Boulton and Peter, 1994; Dölek, 2002; Gültekin, 2003; O'Moore and Hillery, 1989; Pekel-Uludağlı and Uçanok, 2005; Pellegrini, Bartini, and Brooks, 1999). Peer reporting (Pellegrini and Bartini, 2000; Schwartz, 2000; Perry, Kusel, and Perry, 1988). In addition, it is seen that the scales used in the studies are international scales (Dölek, 2002; Gültekin Z., 2003; Kartal, 2008). The Swearer peer bullying scale, whose construct validity was tested in this study, is both a peer reporting and a self-report scale, and it is thought that it will meet a need in this area by addressing peer bullying from 4 dimensions: bully, victim, witness, and especially attitude towards bullying.

Swear purpose is to collect more comprehensive data about the scale of bullying bullying Turkish and Turkey to be adapted, validity, reliability studies were intended to be done. 
In academic year 2019-2020, the research scale was applied to 1048 students representing the fifth, sixth, seventh and eighth grades of secondary schools affiliated to the Directorate of National Education with the permission of Konya Provincial Directorate of National Education.

Swearer Attitudes Towards Bullying Scale: The Bully Attitudinal Scale was adapted in Turkish and used within the scope of the study. The adapted scale was developed by Swearer et al. (2008). The measurement tool has a single factor structure and consists of 14 items.

Translation Process of the Measurement Tool into Turkish: After the decision was made to adapt the measurement tool to Turkish, the responsible author (Dr. Swearer) was contacted and permission was obtained for the scale to be adapted. Translation-back translation method was used in the translation process.

The Turkish form was also examined in terms of cultural context, linguistics, research methodology, assessment and evaluation criteria. Some revisions were made in the scale items based on expert opinions. Before the validity and reliability studies were carried out, the Turkish form was applied to thirty students and their opinions about the scale items were obtained.

The validity of the Swearer Attitude Towards Bullying Scale was examined by exploratory (EFA) and confirmatory (CFA) factor analysis. Before the exploratory factor analysis, the KMO coefficient of the scale was found to be 0.70 and it was observed that the sample size was sufficient. In the next step, Bartlett's test coefficient was calculated and it was observed that the obtained coefficient was significant $(\chi 2=1151.89 ; \mathrm{Sd}=36 ; \mathrm{p}<0.001)$. Construct validity was tested by applying principal components analysis method and confirmatory factor analysis. As a result of EFA, it was observed that the factor loads of the items in the scale varied between 0.40 and 0.82 . The eigenvalue of the single factor structure was calculated as 3.16.

The single-factor structure of the Swearer Attitude Towards Bullying scale discovered by EFA was tested by applying CFA. As a result of the CFA, it was observed that the factor loads of the items in the scale varied between 0.38 and 0.71 . Cronbach alpha internal consistency coefficient was calculated to determine the reliability of the Swearer Attitude Towards Bullying Scale. The alpha coefficient calculated for the scale is 0.74 .

As a result of the validity and reliability analysis, it was observed that Swearer Swearer Attitude Towards Bullying Scale consists of 9 items and has 
a single factor structure. Single factor scale explained a significant proportion of total variance. As a result of the confirmatory factor analysis, the singlefactor structure of the measuring tool was verified. The calculated alpha coefficient showed that the internal consistency of the scale was sufficient. Testretest reliability analysis results indicated that the scale has a stable structure. According to the differential validity results, it showed that each item of the scale was successful in distinguishing students with high and low attitudes towards bullying.

\section{Kaynakça / References}

Akgün, S. (2005). Akran zorbalĭğmın anne-baba tutumları ve anne-baba ergen ilişkisi açısından değerlendirilmesi. Yayınlanmamış yüksek lisans tezi, Hacettepe Üniversitesi, , Ankara.

Alikaşifoğlu, M., Erginöz, E., Ercan, O., Uysal, Ö., ve Albayrak -Kaymak, D. (2007). Bullying behaviors and psychosocial health: Results from a cross-sectional survey among high school students in İstanbul. European Journal of Pediatry, 166, 1253-1260.

Alikaşifoğlu, M., Erginöz, E., Ercan, O., Uysal, Ö., Albayrak- Kaymak, D., ve İtter, Ö. (2004). Violent behaviour among Turkish high school students and correlates of physical fighting. European Journal of Public Health, 14, 173-177.

Aquino, K., ve Bradfield, M. (2000). Perceived victimization in the workplace: The role of situational factors and victim characteristics. Organization Science, 525-537.

Ataman, A. (2003). Özel gereksinimli çocuklar ve özel eğitim. Gereksinimli Çocuklar ve Özel Eğitime Giriş içinde içinde (s. 9-31). Ankara: Gündüz Eğitim ve Yayınc1lik.

Baar, P. (2012). Peer aggression and victimization in Dutch elementary schools and sportclubs:Prevalence, stability, and approach across different contexts. Utrecht: Utrecht University.

Barabady, J., ve Kumar, U. (2008). Reliability analysis of mining equipment: A case study of a Crushing plant at Jajarm Bauxite Mine in Iran. Reliability Engineering ve System Safety, 647-653.

Batu, S., ve Kurcaali Iftar, G. (2011). Kaynaştırma. Ankara : Kök Yayıncllk.

Bayraktar, F. (2009). Ergenlerin zorba ve kurban davranışlarnda birey, aile, akran ve okula dair özelliklerin rolü: Bütüncül bir model önerisi . Yayınlanmamış doktora tezi, Hacettepe Üniversitesi, Ankara.

Berger, K. (2007). Update on bullying at school: Science forgotten? Developmental Review, 91-92. 
Besag, V. (1995). Bullies and victims in schools. Philadelphia: Open University Press.

Boulton, M., ve Peter , K. (1994). Bully/Victim Problems İn Middle-School Children: Stability, Self - Perceived Competence, Peer-Perceptions And Peer-Acceptance. British Journal Of Developmental Psychology, 12, 315-329.

Browne, M., ve Cudeck, R. (1993). Alternative ways of assessing model fit. Sage focus editions.

Rigby, K. ve Slee, P.T. (1991)Bullying among Australian school children: reported behavior and attitudes toward victims. Journal of Social Psychology, 131, 615-627.

Büyüköztürk, Ş. (2006). Sosyal bilimler için veri analizi el kitabı. Ankara: Pegem Yayınları.

Byrne, B. (1989). A Primer of LISREL: Basic assumptions and programming for confirmatory factor analysis models. New York: SSpringer.

Cağn, R. (2010). 'Zorballk Yapan ve zorbalı̆ga maruz kalan çocuklarn kişilik özelliklerinin karşlaştırlması. İstanbul: T. C. Maltepe Üniversitesi Sosyal Bilimler Enstitüsü Psikoloji Anabilim Dalı.

Cappadocia , M., Weiss, J., ve Pepler , D. (2012). Bullying experiences among children and youth with autism spectrum disorders. J Autism Dev Disord.

Card, N., Stucky, B., Sawalani, G., ve Little, T. (2008). Direct and indirect agression during childhood and adolescence: A meta-analytic review of gender differences, intercorrelations, and relations of maladjustment. Child Development, 79, 1185-1229.

Çınkır, Ş., ve Karaman-Kepenekci, Y. (2003). Öğrenciler arası zorbalık. Kuram ve Uygulamada Eğitim Yönetimi, 34, 236-253.

Çokluk, O., Şekercioğlu, G., ve Büyüköztürk, Ş. (2012). Sosyal bilimler için çok değişkenli SPSS ve LISREL uygulamaları. Ankara: Pegem Akademi Yayıncilk.

Deveci, S., Açık, Y., ve Ayar, A. (2008). A survey of rate of victimization and attitudes towards physical violence among school-aged children in Turkey. Child: Care, Health and Development, 25-31.

DeVellis, R. (2003). Scale Development Theory and Applications Second Edition. . SAGEPublications International Educational and Professional Publisher.

Doğan-Ateş, A., ve Yağmurlu, B. (2010). Examining victimization in Turkish schools. European Journal of Educational Studies, 2(1), 31-37.

Dölek, N. (2002). Öğrencilerde zorbaca davranıslarn araştınlması ve bir önleyici program modeli. Yayımlanmış Doktora Tezi, T.C. Marmara Üniversitesi Eğitim Bilimleri Enstitüsü Eğitim Bilimleri Anabilim Dalı, İstanbul. 
Erdur-Baker, Ö., ve Kavşut, F. (2007). Akran zorbalığının yeni yüzü: Siber zorbalık. . Eurasian Journal of Educational Research, 31-42.

Fekkes, M., Pijpers , F., ve Verloove-Vanhorick , S. (2005). Bullying: who does what, when and where? Involvement of children, teachers and parents in bullying behavior. Health Educ Res., 81-91.

Gini, G., ve Pozzoli, T. (2013). Bullied children and psychosomatic problems: A metaanalysis. Pediatrics, 720-729.

Glover, D., Gough, G., Johnson , M., e Cartwright, N. (2010). Bullying in 25 secondary schools: Incidence, impact and intervention. Educational Research, 42, 141-156.

Gültekin, Z. (2003). Akran zorbalı̆̆ın belirleme ölçexi. Yayınlanmamış Yüksek Lisans Tezi, Hacettepe Üniversitesi., Ankara.

Gültekin, Z., ve Sayıl, M. (2005). Akran zorbalığı belirleme ölçeği geliştirme çalışması. Türk Psikoloji Yazılan, 15(8), 47-61.

Hay, D., Payne, A., ve Chadwick, A. (2004). Peer relations in childhood. Journal of Child Psychology and Psychiatry, 84-108.

Huitsing, G., Van der M. -Van Dijk, M., ve Veenstra, R. (2012). Pesten op school: Achtergronden en interventie. Pesten içinde (s. 81-97). Amsterdam: Boom Lemma.

Jöreskog, K., ve Sörbom, D. (1993). LISREL 8: Structural equation modeling with the simplis command language. Lincolnwood: Scientific Software International, Inc.

Kapçı, E. (2004). İköğretim öğrencilerinin zorbalığa maruz kalma türünün ve sıklığ1nın depresyon, kaygı ve benlik saygısı ile ilişkisi. Ankara Üniversitesi Eğitim Bilimleri Fakültesi Dergisi, 1(37), 1-13.

Kartal, H. (2008). İlköğretim okullarında zorbalık yapanlar ve zorbalığa uğrayanlar. E-journal of New World Sciences Academy, 4(3), 712-730.

Koç, Z. (2006). Lise öğrencilerinin zorbalık düzeylerinin yordanması. Yayınlanmamış doktora tezi, Gazi Üniversitesi, Ankara.

Koç, Z. (2006). Lise öğrencilerinin zorbalık düzeylerinin yordanması. Yayınlanmamış doktora tezi, Gazi Üniversitesi, Ankara.

Ladd, G. (2006). Peer rejection, aggressive or withdrawn behavior, and psychological maladjustment from ages 5 to 12: An Examination of four predictive models. Child Development, 822-846.

Li, Q. (2007). New bottle but old wine: A research of cyberbullying in schools. Computers in Human Behavior, 23(23), 1777-1791. doi:10.1016/j.chb.2005.10.005 adresinden alınd 1

McDonald, R., ve Marsh , H. (1990). Choosing a multivariate model: Noncentrality and goodness of fit. Psychological bulletin, 107(2), 247. 
MEB. (2010). Neden nasıl niçin kaynaştırma eğitimi. Ankara.

Mooij, T. (2010). Pesten op de basisschool. W. S. R. Loeber. içinde Amsterdam: SWP. http://dspace.ou.nl/bitstream/1820/2939/7/111\%202010\%20Pesten $\% 20$ op \%20de\%20basisschool.\%20Hfdst.pdf adresinden alınd 1

O’Moore, M., ve Hillery, B. (1989). Bullying in Dublin schools. . Irish Journal of Psychology, 10(3), 426-441.

Ogelman, H., ve Erten, H. (2010). 5-6 Yaş Çocuklarinin Akran İlişkileri ve Sosyal Konumlarinin Okula Uyum Düzeyleri Üzerindeki Yordayici Etkisi. Selçuk Üniversitesi Sosyal Bilimler Enstitüsü Dergisi, 153-163.

Olweus, D. (1993). Bullying at school: What we know and what we can do. Blackwell Publishers.

Olweus, D. (2005). A useful evaluation design, and effects of the Olweus Bullying Prevention Program. Psychology, Crime ve Law, 389-402.

Olweus, D., ve Limber, S. (2010). Bullying in school: Evaluation and dissemination of the Olweus bullying prevention program. American Journal of Orthopsychiatry, 124-134.

Özdamar, K. (2004). Paket Programlar ile İstatistiksel Veri Analizi (Çok Değişkenli Analizler) 2. Eskişehir: Kaan Kitabevi.

Özsoy, Y., Özyürek, M., ve Eripek, S. (1988). Özel Eği-time Muhtaç Çocuklar ve Özel Ĕ̆gitime Giriş.

Pekel, N. (2004). Akran zorbalı̆̆ı grupları arasında sosyometrik başarı durumlarnın incelenmesi. Yayınlanmamış yüksek lisans tezi., Hacettepe Üniversitesi, Ankara.

Pekel-Uludağlı, N., ve Uçanok , Z. (2005). Akran zorbalığı gruplarında yalnızlık ve akademik başarı ile sosyometrik statüye göre zorba/kurban davranış türleri. Türk Psikoloji Dergisi, 57, 77-92.

Pellegrini, A., ve Bartini, M. (2000). An empirical comparison of methods of sampling aggression and victimization in school settings. Journal of Educational Psycho$\log y, 92,360-366$.

Pellegrini, A., ve Long, , J. (2002). A longitudinal study of bullying, dominance, and victimization during the transition from primary school through secondary school. British Journal of Developmental Psychology, 259-280.

Pellegrini, A., Bartini, M., ve Brooks, F. (1999). School bullies, victims and aggressive victims: factors relating to group affiliation and victimization in early adolescence. Journal of Educational Psychology, 91, 216-224.

Pergolizzi, F., Pergolizzi III, J., Gan, Z., Macario, S., Pergolizzi Jr, J., Ewin, T., ve Gan, T. (2011). Bullying in middle school: Results from a 2008 survey. Internationaljournal of Adolescent Medicine and Health(23), 11-18. 
Perry, D., Kusel, S., ve Perry, C. (1988). Victims of peer aggression. Developmental Pschology, 24(6), 807-814., 24(6), 807-814.

Peterson, L., ve Rigby, K. (1999). Countering bullying at an Australian secondary school with students as helpers. Journal of Adolescence, 22, 481-492.

Pişkin, M. (2002). Okul zorbalığ: Tanımı, türleri, ilişkili olduğu faktörler ve alınabilecek önlemler. Kuram ve Uygulamada Eğitim Bilimleri, 531-562.

Pişkin, M., ve Ayas, T. (2011). Akran zorbalığı ölçeği: Çocuk formu. Akademik Bakış Dergisi, 23, 1-12.

Rackwitz, R. (2000). Reliability analysis: A review and some perspectives. Structural Safety, 23, 365-395.

Rigby , K., ve Johnson, B. (2005). Student bystanders in Australian schools. Pastoral Care in Education, 10-16.

Rivers, I., ve Smith, P. (1994). Types of bullying behaviour and their correlates. Aggressive Behavior, 359-368.

Salmivalli, C., ve Nieminen, E. (2002). Proactive and Reactive aggression among school bullies, victim and bully/victims. Aggressive Behavior, 28, 30-44.

Schwartz, D. (2000). Subtypes of victims and aggressors in children's peer groups. Journal of Abnormal Child Psychology, 28, 181-192.

Smith, P., ve Ananiadou, K. (2003). The nature of school bullying and the effectiveness. Journal of Applied Psychoanalytic Studies, 189-209.

Smith, P., Madsen , K., ve Moody, J. (1999). What causes the age decline in reports of being bullied at school? Towards a developmental analysis of risks of being bullied. Educational Research, 267-285. .

Şirvanlı-Özen, D. (2006). Ergenlerde akran zorbalığına maruz kalmanın yaş, çocuk yetiştirme stilleri ve benlik imgesi ile ilişkisi. Türk Psikoloji Dergisi, 58, 77-94.

Şirvanlı-Özen, D. (2006). Ergenlerde akran zorbalı̆ı̆na maruz kalmanın yaş, çocuk yetiştirme stilleri ve benlik imgesi ile ilişkisi. Türk Psikoloji Dergisi, 21(58), 7794.

Tabachnick, B., ve Fidell, L. (2007). Using multivariate statistics (5th edit b.). Boston: Allyn and Bacon.

Tanaka, J., ve Huba, G. (1985). A fit index for covariance structure models under arbitrary GLS estimation. British Journal of Mathematical and Statistical Psycho$\log y, 38,197-201$.

Tavşancıl, E. (2005). Tutumlarm ölçülmesi ve SPSS ile veri analizi. Ankara: Nobel Yayın Dağıtım. 
Tokunaga, R. (2010). Following you home from school: A critical review and synthesis of research on cyberbullying victimization. Computers in Human Behavior, 26, 277-287.

Van der Wal, M., De Wit, C., ve Hirasing, R. (2003). Psychosocial health among young victims and offenders of direct and indirect bullying. . Pediatrics, 1312-1317.

Van Doorn, E., ve Verheij, F. (2010). Adaptief behandelen op school. Assen: Gorcum.

Vandevelde, S., ve De Groef, J. (2015). De sociale inclusie van personen met een verstandelijkebeperking en geestelijke gezondheidsproblemen: druk of drive. Orthopedagogiek: onderzoek en praktijk, 270-283.

Vermande, M., Meulenr, M., Aleva, L., Olthof, T., ve Goossens, F. (2011). Pesten. Amsterdam.

Walker, S. (2004). Teacher reports of social behavior and peer acceptance in early childhood: Sex and social status differences. Child Study Journal, 13-28.

Whitted, K., ve Dupper, D. (2005). Best practices for preventing or reducing bullying in schools. ProQuest Education Journals, 168-175.

Yang, A., ve Salmivalli, C. (2013). Different forms of bullying and victimization: Bully victims versus bullies and victims. European Journal of Developmental Psycho$\log y, 723-738$.

Yildirim, S. (2001). The relationships of bullying, family environment and popularity. Yayınlanmamış yüksek lisans, Orta Doğu Teknik Üniversitesi, Ankara .

Yurtal, F., ve Cenkseven, F. (2006). İlköğretim okullarında zorbalı̆̆ın incelenmesi. 1. Şiddet ve Okul: Okul ve Çevresinde Çocuğa Yönelik Şiddete ve Alnnabilecek Tedbirler Uluslararast Katılımlı Sempozyumu. İstanbul.

\section{Kaynakça Bilgisi / Citation Information}

Efilti, E. ve Özdemir, Ş. A. (2021). Swearer zorbalık ölçeğinin Türk kültürüne uyarlanması ve geçerlilik, güvenilirlik analizi. OPUS-Uluslararası Toplum Araştırmaları Dergisi, 17(35), 2008-2029. DOI: 10.26466/opus.738264 